\title{
Ilustrações para uma metafísica da música a partir de Schopenhauer
}

\author{
Luan Corrêa da Silva \\ Mestrando em Filosofia - UFSC
}

\begin{abstract}
RESUMO: Schopenhauer propõe, em $O$ mundo como vontade e como representação, uma consideração metafísica da música, em oposição a sua consideração física. Mostra, a partir daí, de que maneira a música é expressão da própria essência do mundo e como é possível uma analogia do próprio mundo com ela. Essa tese, que influenciou de imediato pensadores e compositores - representando um salto importante para a compreensão do fenômeno da música - permite-nos refletir a música como não apenas uma expressão do humano, mas como constituinte dele; ou seja, permite-nos mostrar de que maneira a metafísica da música pode ser pensada enquanto uma disciplina independente do autor. Assim, torna-se possível mostrar a relevância do pensamento de Schopenhauer para as experiências contemporâneas da música e, então, inseri-lo de forma efetiva nas discussões atuais.
\end{abstract}

PALAVRAS-CHAVE: Metafísica; Música; Schopenhauer.

ABSTRACT: Schopenhauer proposes, in The world as will and representation, a metaphysic account of music, in contrast with its physical consideration. He shows, from there, in what way the music expresses the very essence of the world and how it is possible to do an analogy of his own world with it. This thesis, which immediately influenced thinkers and composers representing a major leap in the understanding of the music phenomenon - allows us to reflect the music not just as an expression of the human, but as a part of it; that is, permit us to show how the metaphysics of music can be thought of as an independent discipline, unrelated to the author. Thus, it becomes possible to show the relevance of Schopenhauer's thinking for the contemporary experiences of music and, then, make it effectively present in today's discussions

KEYWORDS: Metaphysics; Music; Schopenhauer.

A música foi praticada em todos os tempos sem se questionar pela sua significação profunda, sem se questionar pela sua essência, conta o filósofo alemão Arthur Schopenhauer. Ela nos é tão imediata que uma concepção abstrata dessa compreensão imediata é inevitavelmente dispensável. Ela é compreendida independentemente de qualquer teorização a seu respeito. ${ }^{1}$

Entender isso requer, todavia, a consideração metafísica da música, em oposição ao que seria sua consideração física, ou seja, de sua casca, seu exterior. Um exemplo de como seria considerá-la em sua casca são suas relações aritméticas, como expressa Leibniz quando diz que a música é um "exercício oculto de aritmética no qual a alma

1 Utilizo-me da edição: SCHOPENHAUER, Arthur. $O$ mundo como vontade e como representação. Trad. Jair Barboza. São Paulo: Ed. UNESP, 2005, doravante abreviada como MVR I. 
não sabe que conta."2; ou seja, a música pode ser calculada ${ }^{3}$. Possui relações harmônicas tais que determinando-se suas frequências, determinam-se seus sons; em outras palavras: uma explicação dela em termos matemáticos é bastante plausível e aceita, absolutamente útil e importante para a educação musical, sobretudo torna objetiva (na forma dos campos harmônicos e escalas) a relação do ser-humano com os sons; porém uma explicação dessa não é a explicação da essência da música e não a resume nela. Se fosse assim, diz Schopenhauer, a satisfação que sentimos na audição de uma música teria de ser semelhante a que sentimos na correta resolução de uma soma aritmética e não poderia ser a alegria interior com a qual o íntimo mais fundo do nosso ser é trazido à linguagem ${ }^{4}$. É sinal do que a música é em essência, Vontade.

A música, diferente das outras artes, não é objetivação de Ideia no mundo, mas da própria Vontade, cuja objetidade também são Ideias; ou seja, enquanto as representações artísticas atuam no mundo na condição de serem representações de Ideias, cujo conhecimento puro é o conhecimento delas, a música atua no mundo como manifestação da própria Vontade, ultrapassando, assim, o próprio mundo intuitivo, e isso quer dizer: a própria intuição, modo pelo qual era possível o conhecimento de Ideias, é dispensada. O correlato da Ideia, o sujeito puro, também ${ }^{5}$.

Se a música é, tal como Ideia, manifestação imediata da Vontade, então existe um paralelo entre música e Ideia, ambas estariam por assim dizer no mesmo "nível" de realidade. Deve haver também, então, um correspondente para o puro sujeito do conhecimento ao se tratar da música, para Jair Barboza, ao que Schopenhauer parece nos mostrar, é a fantasia. Ela transforma a audição em imagem, faz-nos viver a partir dos sons o mundo das mais variadas formas, e é por isso que com a música nos sentimos como se diante de nós se desenrolasse uma história, cujos momentos e cenas imediatamente nos aparecessem como em um filme. ${ }^{6}$

Quer dizer, quando Schopenhauer fala que os sentimentos e paixões musicais são experienciados "como que in abstracto", devemos ler: a fantasia atua no lugar do puro sujeito do conhecimento, como que fiando a negação da Vontade ${ }^{7}$. Os sentimentos são experienciados na música não como os experienciamos como indivíduos,

2 SCHOPENHAUER, A. MVR I, § 52, p. 336.

3 Veremos adiante, todavia, que esses cálculos não podem ser aritmeticamente precisos.

4 SCHOPENHAUER, A. MVR I, § 52, p. 337.

5 BARBOZA, A metafísica do belo de Arthur Schopenhauer. São Paulo: Humanitas, 2001, p. 126.

6 BARBOZA, J. Schopenhauer. A decifração do enigma do mundo. São Paulo: Moderna, 1997, p. 75. 
particularmente, para cada caso isolado, esta ou aquela aflição, ou dor, ou espanto, ou júbilo, ou regozijo, ou tranquilidade de ânimo, mas eles mesmos, isto é, a Alegria, a Aflição, a Dor, o Espanto, o Júbilo, o Regojizo, a Tranquilidade de Ânimo ${ }^{8}$, ou seja, "se uma imagem vale mil palavras, uma música vale mil imagens"”; e é por isso que é possível um dos traços mais impressionantes da música, a sua íntima ligação com qualquer cena, ação, acontecimento ou circunstância: quando se combinam harmoniosamente, a música parece desvendar-nos o seu sentido mais secreto e se mostra como seu comentário mais claro e verdadeiro. É como se, diante de uma vista rotineira, a música tivesse a capacidade de vivificá-la a tal ponto que não mais a reconhecêssemos. ${ }^{10}$

O fato da música ser expressão da própria Vontade, ao invés de ser expressão de Ideias, explica também porquê a música se combina tão facilmente com outras artes, como no caso da Poesia que, quando cantada, ganha um significado às vezes surpreendente. Da mesma forma quando tiramos a música de uma poesia, ou quando tiramos a música de uma canção, recitamos as palavras e elas aparecem como que murchas, cinzas, sem muita graça. É por isso que a Ópera, para Schopenhauer, comete um engano quando submete a música ao seu texto, quando o mais coerente seria fazer o contrário. $^{11}$

Tudo isso porque a música é uma linguagem universal, e se há uma, é ela. É linguagem porque a compreendemos ${ }^{12}$ (a música revela o sentido mais íntimo do mundo

7 BARBOZA, J. A metafísica do belo de Arthur Schopenhauer. São Paulo: Humanitas, 2001, p. 128. 8 SCHOPENHAUER, A. MVR I, § 52, p. 343.

9 BARBOZA, J. Schopenhauer. A decifração do enigma do mundo, 1997, p. 75.

10 Jair Barboza escreve uma nota bastante interessante a respeito: "Isso nos leva até a pensar no cinema hollywoodiano, em especial o de Steven Spielberg, em que cada minuto imagético é acompanhado de um tema musical; ou em Hitchcock, para quem a música era uma componente fílmica tão importante quanto a própria imagem: que se lembre da cena de Psicose e que a caveira da mãe de Normam Bates é subitamente revelada, após a viragem de uma cadeira: em vez de gritos, temos os acordes de um violino. O mesmo vale para o teatro. Recentemente foi encenada Macbeth de Shakespeare, por Annes Filho, na qual a cena final, quando o corpo do general escocês é removido, no lugar de impropérios lançados ao cadáver, embebido em sangue, ouvíamos ao fundo uma barulheira de hard rock. Quer dizer, os encenadores contemporâneos parecem, talvez sem sabê-lo, acordar com o dito por Schopenhauer na passagem recém-citada: a música desvenda o "misterioso sentido" de cada cena, acontecimento, sucesso, dispensando as palavras,o discurso. - Nesse ponto, Tarkovski, que defendia o mínimo de música no cinema, é o representante anti-schopenhaueriano: Devo dizer que, do fundo do meu coração, não acredito que os filmes precisem de música... Pois, falando com toda sinceridade, o mundo transformado pelo cinema e o mundo transformado pela música são coisas paralelas e em conflito mútuo." (TARKOVISKI apud BARBOZA, 2001, p. 128) In: BARBOZA, J. A metafisica do belo de Arthur Schopenhauer. São Paulo: Humanitas, 2001, p. 128.

12 Aqui, sem dúvidas, poderíamos tratar de uma distinção pertinente não tratada explicitamente por Schopenhauer mas que de certa forma delineia sua argumentação, da linguagem enquanto um "dizer" e 
a partir de uma compreensão imediata), e é universal pois é a própria essência do mundo que se apresenta diretamente a nós, a manifestação mais imediata da essência do mundo; não como uma universalidade vazia da abstração, mas de um tipo totalmente diferente, ligada a uma determinação mais distinta e contínua ${ }^{13}$. Dessa forma, a música é para os diferentes sons o que a Vontade é para as diferentes Ideias, as diferentes espécies do mundo: tão independente dessas quanto é essencial. Ora, se é a mesma Vontade que se objetiva tanto nas Ideias quanto na música, embora de maneira bem diferente em cada uma delas, deve haver entre música e Ideia, afirma Schopenhauer, um paralelismo, uma analogia, cujo fenômeno na pluralidade e imperfeição é o mundo visível.

Por se tratar de um assunto tão obscuro como a música, tão fugaz e indefinível, quando alvo de investigação filosófica, parece-nos difícil, e até impossível, uma exposição que consiga dar conta de sua experiência, que consiga corresponder à sua própria audição. De fato, como dissemos, por ser tão imediata e primordial, fica difícil de encontrar seu parâmetro fenomênico no mundo, a ponto de nos poder ser possível sua comparação, não muito fiel, com uma infinidade de coisas e circunstâncias com semelhante êxito. Entretanto, Schopenhauer nos oferece uma analogia bastante interessante entre a música e o Mundo, entre as manifestações da música em sons e as espécies do mundo; uma analogia que, porém, não deve lida ao pé da letra, mas encarada apenas como uma analogia, que nos servirá para um maior entendimento filosófico da estreita ligação da música com a Vontade, o que de fato nos interessa. Uma analogia que somente faz sentido com a audição musical frequente, com seu contato bruto. $^{14}$

Da mesma forma, diz Schopenhauer, que nenhuma matéria é perceptível sem forma e qualidade, assim também o som grave tem um limite além do qual som nenhum

dela enquanto um "comunicar", o que me habilitaria a falar de uma "comunicação sem conceitos" no pensamento de Schopenhauer, o caso da música: diferentemente da ciência, ela nos comunica a essência do mundo por meio de sons sem precisar usar um único conceito, uma única palavra. Sobre o "conceito", há uma passagem interessante no texto: “(...) O conceito, por mais útil que seja para a vida, e por mais usado, necessário e proveitoso que seja na ciência, é no entanto eternamente infrutífero para a arte. A verdadeira e única fonte de qualquer obra de arte é a Ideia apreendida. Esta, em sua originariedade vigorosa, é haurida apenas da vida mesma, da natureza, do mundo, pelo gênio autêntico ou por quem se entusiasma instantaneamente até a genialidade. Somente dessa receptividade imediata se originam as autênticas obras de arte, a portarem em si vida imortal. Justamente porque a Ideia é e permanece intuitiva, o artista não está consciente in abstracto da intenção e do fim de sua obra; não um conceito, mas uma Ideia paira diante de si: por conseguinte, não pode relatar sua atividade: trabalha, como se diz, com o simples sentimento, inconsciente, sim, de maneira instintiva" (SCHOPENHAUER, A. MVR I, § 49, p. 312). Daí o aspecto irracionalista de sua filosofia, onde a verdade nos é expressa "irracionalmente".

13 SCHOPENHAUER, A. MVR I, § 52, p. 344. 
é audível. Isto é, assim como o som depende de um certo grau de altura, matéria nenhuma pode ser separada de um certo grau de exteriorização. Mesmo o som mais grave possui o mínimo de vibração; no mundo, essa vibração na matéria é a sua volição, e é por isso que até mesmo uma pedra possui "vida", já que a Vontade é no fundo a Vontade de vida, mesmo que "Vontade" e "Vida" possam ser considerados como sinônimos. Em termos físicos: quanto maior a vibração, isto é, quanto mais agudo o som, maior é o grau de determinação da Vontade. ${ }^{15}$

Analogamente, todos os corpos e organismos da natureza têm sua origem na massa do planeta, a partir de um desenvolvimento gradativo, que é tanto seu sustentáculo, como sua fonte; o próprio planeta que nos gera é aquele que nos alimenta, e nosso alimento também é gerado por ele. O baixo contínuo ${ }^{16}$ é na música, portanto, o que no mundo é a natureza inorgânica: "sobre a qual tudo se assenta e a partir da qual tudo se eleva e desenvolve"17. A partir dele, surgem os sons intermediários da harmonia, composta por diferentes tons ligados entre si, corresponde, em uma composição, aos sons intermediários entre o baixo e a melodia: os mais baixos correspondem aos seres ainda não orgânicos ou menos orgânicos, e os mais altos correspondem aos vegetais e animais. Assim, como se vê, intervalos determinados e bem definidos entre os sons são como a distinção entre as diferentes espécies do mundo, da mesma forma que a indeterminação precisa desses intervalos, o desvio aritmético deles, representa desvio do indivíduo do tipo da espécie, um "patinho feio" no meio dos outros. Uma dissonância impura, ou seja, aquela que não forma um intervalo determinado, é comparável, diz Schopenhauer, aos abortos monstruosos entre duas espécies de animais, ou entre um homem e um animal. E a passagem de uma tonalidade para outra completamente diferente, quando a conexão com a anterior é totalmente interrompida, compara-se à morte, na medida em que nela o indivíduo chega ao fim; ao mesmo tempo em que essa morte abre espaço para que outra vida surja e logo um novo indivíduo nasce, e a vida continua a se afirmar. ${ }^{18}$

\footnotetext{
14 SCHOPENHAUER, A. MVR I, § 52, p. 338.

15 SCHOPENHAUER, A. MVR I, § 52, p. 339.

16 O baixo contínuo é o som mais grave de uma composição destinado a sustentá-la. O baixo é a fundação de uma harmonia de 4 vozes, em que se estabelece a tonalidade de cada acorde dentro da música diatônica ocidental. Sobre a origem do baixo continuo e outros aspectos históricos da música ocidental, ver: GROUT, Donald J.; PALISCA, Claude V., History of Western Music. Norton, Londres, 2001.

17 SCHOPENHAUER, A. MVR I, § 52, p. 339.

18 SCHOPENHAUER, A. MVR I, § 52, p. 340.
} 
O movimento é aqui uma característica bastante presente entre esses graus de determinação. Vemos que enquanto o baixo se movimenta de uma forma mais lenta, pesarosa, de maneira um pouco mais ágil aparecem os sons da harmonia, ambas, entretanto, ainda sem um desenvolvimento significativo, ainda transparecem como que caoticamente, desordenadamente, como se ali faltasse um narrador, aquele que ordena o caos, dá sentido ao mundo, o ser-humano. "O animal e a planta são a quinta e a terceira menores do homem: o reino inorgânico a sua oitava inferior". ${ }^{19}$

É então que surge a Melodia, aquela voz mais aguda que desliza pela harmonia; é ela que oferece a conexão de sentido, o elemento "racional" da música. Ela também que dá a "cara" de uma canção, representando o caráter individual da melodia, que distingue o ser-humano do restante dos animais, ela que faz com que, por exemplo, reconheçamos as canções que ouvimos, que parece-nos fixar justamente por aquela voz peculiar sem a qual dificilmente as reconheceríamos, assim, o número inesgotável de possíveis melodias corresponde ao inesgotável da natureza na diversidade de seus indivíduos, fisionomias e discursos de vida. ${ }^{20}$

A comparação com o ser-humano vai mais além: da mesma forma que a essência do humano consiste no eterno querer, no vagar entre o desejo e a satisfação sem cessar, onde a felicidade e o bem-estar não surgem da satisfação completa mas do passar de um para o outro com maior rapidez, uma vez que a ausência de satisfação é sofrimento, e a do novo desejo, ansiedade vazia, tédio; dessa mesma forma, então, a essência da melodia é vagar entre o desejo e a satisfação, ou seja: vagar da consonância para a dissonância, desviando do tom fundamental por mil caminhos, não só entre os graus próprios de sua tonalidade, mas também para dissonâncias puras como a sétima, nona, e graus ulteriores. Mas sempre enquanto desvios não muito longos e sempre com o retorno ao tom fundamental: por esses caminhos a melodia exprime o impulso da Vontade, o vagar do desejo para a satisfação, do eterno sofrimento. É assim que se constitui a linha melódica de uma canção: da mesma forma que a passagem veloz do desejo à satisfação e dessa para um novo desejo constitui, como vimos, em felicidade e bem-estar, também melodias ligeiras e sem muitos desvios são alegres; é por isso que 
melodias lentas, resultando em dissonâncias dolorosas que somente retornam ao tom original compassos além, são melancólicas, de satisfações tardias, sofridas. ${ }^{21}$

“Quão maravilhoso é o efeito dos modos maior e menor!", espanta-se Schopenhauer com o incrível efeito que nos causa a mudança de apenas um semitom ${ }^{22}$ em um dos graus de formação do acorde, ou seja, um detalhe que nos faz toda a diferença. Enquanto que um acorde maior nos causa uma sensação de conforto, satisfação, o mesmo acorde menor nos causa angústia, falta, como se algo ali faltasse. Enquanto, para o autor, o adagio atinge no modo menor a expressão mais aguda da dor, tornando-se um lamento dos mais comoventes, a música de dança, em modo menor, parece-nos indicar a perda da felicidade frívola, que antes se deveria desprezar, parecenos contar o sucesso de um fim mesquinho às custas de esforços e sacrifícios.

A "invenção" da melodia, diz o autor de O mundo como Vontade e como Representação, esse desvelamento dos mais íntimos e profundos segredos do querer e do sentir humanos, da essência mais íntima do mundo e a mais profunda sabedoria, em uma linguagem incompreensível à sua razão; é tudo isso obra do gênio, cuja atuação aqui se situa como ainda mais evidente que agora se situa longe de qualquer reflexão ou intencionalidade, muito mais próximo da intuição, quase que como alguém hipnotizado. É por isso que no compositor, mais do que em qualquer outro artista, o homem é inteiramente separado do artista. O artista aparece mais no domínio da pura fantasia do que do puro sujeito, como anteriormente mencionamos.

Apesar de ser determinante para o conjunto de uma obra, a melodia não existe sozinha e separada dos demais componentes da música, a voz aguda condutora da melodia precisa do acompanhamento de todas as outras vozes, até o baixo mais grave, que deve ser visto como a origem comum de todas; a melodia penetra na harmonia como sua parte integrante e vice e versa: assim como, portanto, somente no conjunto de todas as vozes a música se exprime, também a Vontade só pode encontrar sua objetivação perfeita no conjunto completo de todos os seres que manifestam sua essência.

Apesar da conformidade recíproca entre as manifestações da Vontade no mundo, das espécies convivendo entre si em um ciclo interminável e constante, harmonioso,

21 SCHOPENHAUER, A. MVR I, § 52, p. 342.

22 "Semitom" é o menor intervalo da escala diatônica e cromática, as escalas utilizadas nas composições de grande parte da música popular, hoje. 
como se houvesse uma inteligência ordenadora, existe entre esses fenômenos, porém, uma luta eterna que percorre todos os degraus da hierarquia, é a natureza autodiscordante da Vontade que mostra o antagonismo dela consigo mesma ${ }^{23}$. Com a música ocorre algo análogo: também a harmonia dos sons dentro de um campo harmônico determinado, um sistema de sons perfeitamente puro e harmônico, não é só física, mas aritmeticamente impossível ${ }^{24}$. Os próprios números através dos quais os tons, as notas, se expressam, possuem irracionalidades insolúveis e escala nenhuma pode sequer ser computada, pois se as notas se referem precisamente ao tom fundamental, como terça, quinta ou sétima, por exemplo, não conseguem o mesmo entre si, comparáveis, diz Schopenhauer, aos atores, que ora representam um papel, ora outro, dependendo da peça apresentada. Daí porque uma música perfeitamente correta jamais pode ser concebida, que dirá executada. O que se pode, sim, é ocultar sua dissonância essencial pela distribuição da mesma em todos os tons através de um temperamento. ${ }^{25}$

Música e natureza são, portanto, duas expressões distintas de uma mesma coisa, e essa coisa é a Vontade, única intermediadora da analogia de ambas. Analogia que só é possível porque ela não é, diferente de todas as artes, cópia de Ideia, mas objetivação direta da Vontade. Portanto, ela expõe para todo o físico o metafísico, para todo

23 Lembro aqui do argumento teleológico da existência de Deus, ou simplesmente "argumento do desígnio", apresentado em uma de suas formas, mais contemporânea, por Richard Dawkins como a "analogia do relojoeiro". O argumento consiste em defender que, do mesmo modo que, perante um relógio, podemos pressupor a existência de um ser inteligente que o tenha construído segundo um determinado fim, também diante do mundo podemos pressupor igualmente, por analogia, a existência de um ser inteligente que o tenha construído segundo um determinado fim, dadas as semelhanças entre um relógio e o mundo. Assim, da mesma forma que achamos absurdo que a natureza crie um relógio, dada sua complexidade, também parece-nos absurdo que nós, criadores objetos tão complexos quanto os relógios, sejamos criados por algo que não seja inteligente. Schopenhauer pensa ser enganosa a premissa de que o mundo é harmoniosamente ordenado com o argumento da vontade auto-discordante - a constatação de que não só de harmonia o mundo é constituído, mas também da desarmonia expressa na luta dos seres no mundo e no sofrimento, característica marcante do pensamento do autor -, além da natureza irracional e caótica da Vontade, essência do mundo. Sobre a "analogia do relojoeiro" ver: DAWKINS, R. (1986) O Relojoeiro Cego.

24 SCHOPENHAUER, A. MVR I, § 52, p. 348.

25 Oscar João Abdounur nos informa sobre a necessidade do Temperamento: "O Temperamento no sentido geral significa uma escala em que todos ou quase todos os intervalos apresentam-se ligeiramente imprecisos, porém não distorcidos (SADIE apud ABDOUNUR, Oscar João. Matemática e Música: $O$ pensamento analógico na construção de significados. São Paulo: Escrituras Editora, 2006). O sentido de Temperamento aqui utilizado refere-se ao temperamento igual em que se divide o intervalo de oitava em 12 semitons associados a relações de frequências exatamente iguais. Assim como os percursos de quintas apresentados não perfaziam os de oitavas, não é difícil observar que quaisquer ciclos de intervalos naturais - relações matemáticas simples - não se encaixam entre si, o que intima a necessidade de algum temperamento (...). De maneira geral, os temperamentos acabam por valorizar alguns intervalos em detrimento de outros, no sentido de que aos primeiros correspondem mesmas relações de frequência diferentemente dos restantes". Ver mais sobre Temperamento em: ABDOUNUR, Oscar João. Matemática e Música: O pensamento analógico na construção de significados. São Paulo: Escrituras Editora, 2006. 
fenômeno a coisa-em-si, a ponto de nos ser possível denominar o mundo tanto como Vontade corporificada, quanto música corporificada. Eis um ponto crucial dessa analogia, onde o caminho é de mão dupla, tanto a consideração metafísica do mundo nos possibilita uma maior compreensão filosófica da música, quando o contrário, e é por isso que, como se percebeu, frequentemente a analogia se inverteu sem que com isso nossa compreensão do mundo ou da música tenham se perdido. É aí que nos damos conta de que no fundo, diria Schopenhauer, talvez seja a música que nos faça melhor compreender o mundo, e não o contrário, e é por isso que, já no final do terceiro livro de sua obra principal, o autor dirá que é a metafísica da música, portanto, a verdadeira filosofia.

José Miguel Wisnik, em seu livro intitulado "O som e o sentido" de 1989, propõe por via de um ensaio o que ele chama de uma nova história da música, guiada pela natureza íntima do som. Ele mostra que, no decorrer dessa história atravessada pelas diversas manifestações do humano, podemos reconhecer os constituintes básicos dos sons nas mais variadas formas, "som" e "ruído" e "silêncio" passam a ser tratados, portanto, como conceitos metafísicos ${ }^{26}$.

O próprio som, enquanto onda, constata Wisnik, é o passar da tensão para o conforto, da insatisfação para a satisfação. No reconhecer a música enquanto um fenômeno físico, na forma da onda, reconhecemos nela também a sua ligação com o íntimo humano; a própria onda é ela mesma "tensão" e "conforto". Além disso, a pulsação que, como diz Wisnik, é reflexo de "ritmos humanos", o que ele mesmo denomina por ritmos somáticos (sanguíneo) e psíquicos (ondas cerebrais), é "interpretada", e isso quer dizer: "interage" com uma certa disposição do próprio humano $^{27}$. Exemplos de ritmos podemos dizer: a batida do coração, na pulsação do sangue, no ritmo da respiração, no andar (de onde vem "andamento"), no piscar dos olhos, etc. $\mathrm{O}$ autor nos mostra como esses ritmos são de maneira primordial reflexo dos

\footnotetext{
$26 \mathrm{Na}$ orelha do livro podemos ler: "A tese é que a evolução da linguagem musical do Ocidente desenha um círculo, ou melhor, um percurso em espiral que oscila entre duas alternativas colocadas pela própria natureza do som e do nosso corpo: a pulsação (o batimento cardíaco) e a frequência (a onda cerebral). Uma oposição que, atravessando diagonalmente todas as práticas (canto/dança) e todas as técnicas musicais (serialismo/minimalismo, para focar apenas entre as mais recentes), repousa na natureza última do som, no corpo em vibração que é simultaneamente pulsação e frequência" (Cf. WISNIK, José Miguel. O som e o sentido. São Paulo: Companhia das letras, 1989). Mais adiante veremos sobre a experiência de John Cage na câmara anecoica.
} 
ritmos humanos, e interessantemente cita Johann Joachim Quantz que teria dito em "método para flauta transversal", de 1752, que o padrão regular de todos os andamentos seria "o pulso de uma pessoa de bom humor, fogosa e leve, à tarde".

“Toda música está cheia de inferno e céu”, pulsos estáveis e instáveis, ressonâncias e defasagens, curvas e quinas ${ }^{28}$. Toda onda não é meramente uma onda, os sinais sonoros são complexos e sobrepostos, com distinções de alturas, frequências e timbres, sobre o qual predominam alguns que reconhecemos com maior facilidade. É o diálogo dessas complexidades sonoras, tempo e contratempo, dissonância e consonância) que engendra as músicas ${ }^{29}$. Isso revela como uma Harmonia se constrói a partir de um diálogo sonoro, mais propriamente um "debate sonoro", e às vezes até uma discussão fervorosa; quer dizer, uma interação entre sons distintos. Não houvesse essas complexidades, não haveria som. Uma luta interna é travada para que possamos reconhecer em um só som como estável, "harmônico".

A partir disso é que nos é possível pensar na consideração metafísica da música, no que diz respeito, por exemplo, ao caos e ordem e, consequentemente, na sua dimensão política: isso quer dizer: culturas são expressas pela música, de certa forma exprimem uma dada estrutura política, daí que a música tonal, estruturada, dos sons aparentemente precisos, expressaria uma dada cultura ocidental que tem sua política estruturada como tal; "um único som musical afinado diminui o grau de incerteza no universo, porque insemina nele um princípio de ordem". ${ }^{30}$ Ademais:

Um único som afinado, cantado em uníssono por um grupo humano, tem o poder mágico de evocar uma fundação cósmica: insemina-se coletivamente no meio dos ruídos do mundo, um princípio ordenador [...] sobre uma frequência invisível, trava-se um acordo, antes de qualquer acorde, que projeta não só o fundamento de um cosmos sonoro, mas também do universo social. ${ }^{31}$

Wisnik constata que no mundo modal (sociedades pré-capitalistas) a música foi vivida como uma experiência do sagrado, porque nela se travaria, a cada vez, a luta

27 WISNIK, José Miguel. O som e o sentido. São Paulo: Companhia das letras, 1989, p. 20.

28 WISNIK, José Miguel. O som e o sentido. São Paulo: Companhia das letras, 1989, p. 23.

29 WISNIK, José Miguel. O som e o sentido. São Paulo: Companhia das letras, 1989, p. 26.

30 ATALLI apud WISNIK, José Miguel. O som e o sentido. São Paulo: Companhia das letras, 1989, p. 27. Para o aprofundamento neste tema, ver: ATALLI, Jacques. Bruits - Essai sur l'économie politique de la musique, Paris, PUF, 1977.

31 WISNIK, José Miguel. O som e o sentido. São Paulo: Companhia das letras, 1989, p. 33. 
cósmica e caótica entre o som e o ruído. "As sociedades existem na medida em que possam fazer música" ${ }^{33}$, ou seja, "travar um acordo mínimo sobre a constituição de uma ordem”, entre as violências internas e as violências externas, a luta pela sobrevivência, tal como em Schopenhauer, tem o mesmo sentido metafísico da luta de um povo pela conquista de um território, ou pela hegemonia econômica.

Partindo do que habitualmente chamamos de "ruído sonoro", e combinando com a definição do conceito dado pela teoria da informação, a saber, de que ruído é qualquer interferência no âmbito da comunicação, Wisnik abandona uma possível abordagem natural do conceito para adotar uma relacional.

O som periódico opõe-se ao ruído, formado de feixes de defasagens “arrítmicas" e instáveis (...) no entanto, o grau de ruído que se ouve num som varia conforme o contexto. Um intervalo de terça maior (como o que há entre as notas dó e mi) é dissonante durante séculos, no contexto da primeira polifonia medieval, e torna-se plena consonância na música tonal. Um grito pode ser um som habitual no pátio de uma escola e um escândalo na sala de aula ou num concerto de música clássica. Uma balada "brega" pode ser embaladora num baile popular e chocante ou exótica numa festa burguesa (onde pode se tornar frisson chique/brega). Tocar um piano desafinado pode ser uma experiência interessante no caso de um ragtime e inviável em se tratando de uma sonata de Mozart. Um cluster (acorde formado pelo aglomerado de notas juntas, que um pianista produz batendo o pulso, a mão ou todo o braço no teclado) pode causar espanto num recital tradicional sem deixar de ser tedioso e rotinizado num concerto de vanguarda acadêmica. Um show de rock pode ser um pesadelo para os ouvidos do pai e da mãe e, no entanto, funcionar para o filho como canção de ninar no mundo do ruído generalizado. ${ }^{34}$

Considerando, portanto, seu aspecto relacional, "ruído" será definido por Wisnik como um "elemento virtualmente criativo, desorganizador de mensagens/códigos cristalizados e provocador de novas linguagens"35. Pensar no ruído enquanto um elemento desornador criativo será pensá-lo como um conceito relacional, daí porque em diferentes culturas identificamos ruídos diferentes; apesar de que não como conceito fixo: o que um dia foi ruído hoje é som, e amanhã pode vir a se tornar silêncio. É

32 Lembro que "luta cósmica" remete imediatamente a Schopenhauer e às dicotomias "ordem/caos", "vida/morte", "satisfação/sofrimento", "afirmação/negação", isto é, àquela natureza auto-discordante da Vontade a qual vimos em Schopenhauer.

33 WISNIK, José Miguel. O som e o sentido. São Paulo: Companhia das letras, 1989, p. 33.

34 WISNIK, José Miguel. O som e o sentido. São Paulo: Companhia das letras, 1989, p. 32.

35 WISNIK, José Miguel. O som e o sentido. São Paulo: Companhia das letras, 1989, p. 33. 
precisamente no ruído que encontramos a potência do som. Esses três conceitos, intercambiáveis como vimos, será, assim, a base sobre a qual a música irá se inscrever, a partir da qual a música enquanto tal se constitui, inevitavelmente:

O som do mundo é o ruído, o mundo se apresenta para nós a todo momento através de frequências irregulares e caóticas com as quais a música trabalha para expressar-lhes uma ordenação (ordenação que contém também margens de instabilidade, com certos padrões sonoros interferindo sobre outros). ${ }^{36}$

O que Wisnik nos sugere ao investigar o sentido mais profundo do fenômeno da música nas mais variadas formas, é que padrões musicais não são fixos, e facilmente quebrados, e por isso que dissonâncias e ruídos aos ]poucos vão tomando lugar na música, deixam de ser encarados como tal, e logo são substituídos. Definir a música como a "arte dos sons" não parece, se aceitamos esta exposição, suficiente e claro, manifestando-se, pois, a necessidade por uma extensão do próprio conceito de música, que seja fundada nessa tricotomia antes mencionada.

John Cage é uma outra boa ilustração de como pensar uma metafísica a partir do que foi dito, sua obra é permeada por essa tricotomia das mais variadas formas. Como conta Augusto de Campos num prefácio para "De segunda a um ano":

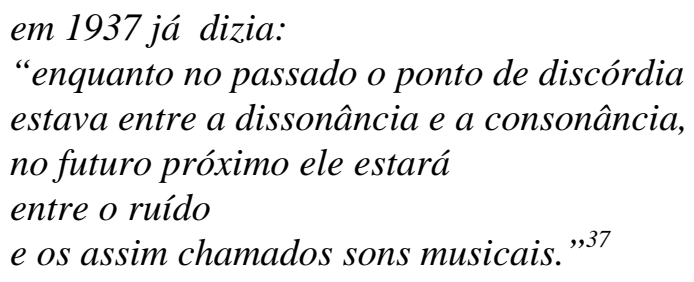

Augusto de Campos conta que Arnold Schoenberg, que lhe dava aulas de graça sob a condição de devotar a sua vida à música, certa vez o recriminou pelo seu descaso pela harmonia dizendo-lhe que para um músico isso era o mesmo que defrontar-se com um muro; e Cage, ainda jovem, teria respondido: "nesse caso eu devotarei a minha vida a bater a cabeça nesse muro", manifestando, assim, seu enorme apreço pelo ritmo e sua insatisfação pelos padrões musicais de sua época. Na verdade uma insatisfação que ia bastante além do mero menosprezo à harmonia, era uma insatisfação da consideração da 
música enquanto tal, que vinha a associar a música diretamente aos seus sons e, consequentemente, às suas relações harmônico-melódicas.

Algumas experiências de Cage são particularmente interessantes, a começar pela famosa 4'33", que consiste numa peça para piano sem sons, o pianista sobe ao palco e senta-se como se fosse tocar o piano, mas na verdade não toca uma só nota, por 4'33", e a música constitui-se, assim, das tosses, risos e os protestos do público, incapazes de curtir quatro minutos e alguns segundos de silêncio ${ }^{38}$. Daí também sua experiência na câmara anecoica (a prova de som), onde esperava experienciar o silêncio absolutamente e falhou. Na verdade ouviu dois sons: um agudo e um grave, o agudo era do sistema nervoso e o grave do sangue em circulação, de onde concluiu que enquanto estivermos vivos, não ouviremos o silêncio absoluto. A própria vida, podemos dizer disso, se expressa musicalmente.

John Cage nos mostra que o silêncio é, antes de qualquer outra coisa, integrante do som, tem parte nele. 4'33" tira o som do silêncio, traz a música para domínios ignorados, revela que na interação entre som ou ruído e silêncio reside a possibilidade da música, mostra que "nenhum som teme o silêncio que o extingue e não há silêncio que não seja grávido de som"39 . Este é John Cage, a condução ao absurdo de tudo o que foi dito. Em radiomusic, uma música que consiste inteiramente nos ruídos provocados pelas ondas de radio, aquelas que aparecem quando estamos entre uma estação e outra, Cage faz do ruído, som. Anuncia, juntamente com Stravinsky ${ }^{40}$, a abertura necessária para o Rock, onde o ruído se tornará a própria matéria do som, expresso na microfonia ${ }^{41}$.

\section{Coda}

A melodia é, seguindo a analogia com a natureza proposta por Schopenhauer, o homem, isto é, o maior grau de objetivação da vontade. É ela a racionalidade da música, é nela, parece, que o sentido se instaura, dada sua íntima relação com a essência do mundo e isso quer dizer: com ela a música ganha uma história, um fio condutor, um

38 CAGE, John. De segunda a um ano. Trad. Rogério Duprat. São Paulo: Ed. Hucitec, 1985, p. 14.

39 CAGE, John. De segunda a um ano. Trad. Rogério Duprat. São Paulo: Ed. Hucitec, 1985, p. 14.

40 Considerado por Wisnik de certa forma o precursor do que chamamos hoje de Rock. (WISNIK, José Miguel. O som e o sentido. São Paulo: Companhia das letras, 1989, p. 44). 
todo de sentido único, sem usar uma palava ou o que for que represente ela. Pela melodia, então, é que se conta uma história universal, não daquele ou outro exemplo individual de humano, mas ele enquanto tal. Assim, não é o filósofo quem conta a história da Vontade enquanto em-si do mundo, daquilo que existe por trás das representações, mas a própria música - diferente do que pensa o idealismo alemão que o autor tanto quer combater - só ela é capaz de exprimir a Vontade de forma tão universal que seja capaz de ser compreensível por qualquer ser no mundo, No fundo, é a própria Vontade que se conta por intermédio dos sons já que a música é a linguagem direta do em-si, como que seu "dialeto nativo". A busca pelo sentido é, portanto, uma busca humana, uma busca "melódica".

Descobrir o sentido mais íntimo e profundo da música, é descobrir que uma escala pode ser descoberta, revelada com os ouvidos; não com a leitura de um manual, mas na sua execução "deformada" (sem forma), de onde é possível sua liberdade, nas inúmeras possibilidades que emergem daí. O pensamento exposto é "metafísico" na medida em que não se faz necessário remeter-se necessariamente à música moderna, do tempo que vive Schopenhauer. Se há uma historicidade ali, ela fica na ordem dos exemplos, e não do que eles exprimem, é uma historicidade que poderíamos chamar "interposta", não "anteposta”. Então, apesar da estrutura musical moderna indicar um certo modelo, ela não elimina sua relação íntima com o mundo, ao qual esse modelo se insere. No fundo, o esforço de Schopenhauer é o de mostrar como nos sons reconhecemos o mundo, tal como o exposto por ele. É uma relação que nos parece estranha, e não se sabe ao certo a causa - se é a tradição cristã (de um Deus fora do mundo, transcendente, absolutamente indeterminado por ele, mas que determina-o) ou se o que talvez pudéssemos nos referir por um certo "cartesianismo" (da distinção entre o eu-pensante como primeira certeza do resto, já incerto). Mas certamente trata-se de uma retomada ao pensamento que advém de um certo monismo pré-socrático de reconhecer em cada humano a própria constituição do mundo. Dentre outras coisas, o que penso que faz Schopenhauer é identificar no seu tempo o que é "silêncio", "som" e "ruído"; inscreve-se na música de sua época e o que ela representa, mas ao mostrar seu sentido oculto, revela-o metafísico.

41 A maioria das pessoas descreve a microfonia como aquele barulho horrível agudo gerado pelo choque de frequências entre microfones e amplificadores, alguns músicos veem nesse barulho um horizonte aberto para suas composições. 


\section{Referências bibliográficas}

ABDOUNUR, Oscar João. Matemática e Música: $O$ pensamento analógico na construção de significados. São Paulo: Escrituras Editora, 2006.

ATALLI, Jacques. Bruits - Essai sur l'économie politique de la musique. Paris: PUF, 1977.

BARBOZA, Jair. Schopenhauer. A decifração do enigma do mundo. São Paulo: Moderna, 1997.

2001.

. A metafísica do belo de Arthur Schopenhauer. São Paulo: Humanitas,

CAGE, John. De Segunda a um ano. Trad. Rogério Duprat revista por Augusto de Campos. São Paulo: Hucitec, 1985.

DAWKINS, Richard. O Relojoeiro Cego. Trad. Isabel Arez. Lisboa: Edições 70, 1988.

GROUT, Donald J.; PALISCA, Claude V., History of Western Music. Norton, Londres, 2001 .

SCHOENBERG, Arnold. Harmonia. Prefácio, tradução e notas de Marden Maluf. São Paulo: Ed: UNESP, 2001.

SCHOPENHAUER, Arthur. Metafísica do Belo. Trad. de Jair Barboza. São Paulo: Ed. UNESP, 2003.

Barboza. São Paulo: Ed. UNESP, 2005.

WISNIK, José Miguel. O som e o sentido. São Paulo: Companhia das Letras, 1989. 